\title{
Sensitivity of hypoxia predictions for the northern Gulf of Mexico to sediment oxygen consumption and model nesting
}

\author{
Katja Fennel, ${ }^{1}$ Jiatang Hu, ${ }^{1,3}$ Arnaud Laurent, ${ }^{1}$ Martinho Marta-Almeida, ${ }^{2}$ and \\ Robert Hetland ${ }^{2}$ \\ Received 30 August 2012; revised 10 December 2012; accepted 7 January 2013; published 28 February 2013.
}

[1] Every summer, a large area $\left(15,000 \mathrm{~km}^{2}\right.$ on average $)$ over the Texas-Louisiana shelf in the northern Gulf of Mexico turns hypoxic due to decay of organic matter that is primarily derived from nutrient inputs from the Mississippi/Atchafalaya River System. Interannual variability in the size of the hypoxic zone is large. The 2008 Action Plan put forth by the Mississippi River/Gulf of Mexico Watershed Nutrient Task Force, an alliance of multiple state and federal agencies and tribes, calls for a reduction of the size of the hypoxic zone through nutrient management in the watershed. Comprehensive models help build mechanistic understanding of the processes underlying hypoxia formation and variability and are thus indispensable tools for devising efficient nutrient reduction strategies and for building reasonable expectations as to what responses can be expected for a given nutrient reduction. Here we present such a model, evaluate its hypoxia simulations against monitoring observations, and assess the sensitivity of the hypoxia simulations to model resolution, variations in sediment oxygen consumption, and choice of physical horizontal boundary conditions. We find that hypoxia simulations on the shelf are very sensitive to the parameterization of sediment oxygen consumption, a result of the fact that hypoxic conditions are restricted to a relatively thin layer above the bottom over most of the shelf. We show that the strength of vertical stratification is an important predictor of dissolved oxygen concentration in bottom waters and that modification of physical horizontal boundary conditions can have a large effect on hypoxia simulations because it can affect stratification strength.

Citation: Fennel, K., J. Hu, A. Laurent, M. Marta-Almeida, and R. Hetland (2013), Sensitivity of hypoxia predictions for the northern Gulf of Mexico to sediment oxygen consumption and model nesting, J. Geophys. Res. Oceans, 118, 990-1002, doi:10.1002/jgrc.20077.

\section{Introduction}

[2] The Texas-Louisiana shelf (TX-LA shelf) experiences low concentrations of dissolved oxygen (referred to as

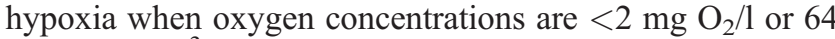
mmol $\mathrm{O}_{2} \mathrm{~m}^{-3}$ ) every summer. The spatial extent of the area affected by hypoxia has increased since the 1950s in parallel with increases in river nitrate loads from the Mississippi/ Atchafalaya River System [Rabalais et al., 2002]. Since 1985, the spatial extent of hypoxic conditions has been monitored systematically with at least one shelf-wide

All Supporting Information may be found in the online version of this article.

${ }^{1}$ Department of Oceanography, Dalhousie University, Halifax, Canada.

${ }^{2}$ Department of Oceanography, Texas A\&M University, College Station, Texas, USA.

${ }^{3}$ School of Environmental Science and Engineering, Sun Yat-Sen University, Guangzhou, China.

Corresponding author: K. Fennel, Department of Oceanography, Dalhousie University, PO Box 15000, Halifax, NS B3H 4R2, Canada. (katja.fennel@dal.ca)

(C) 2013 American Geophysical Union. All Rights Reserved. 2169-9275/13/10.1002/jgrc.20077 monitoring cruise typically in late July or early August. The long-term average size of the hypoxic area is $15,000 \mathrm{~km}^{2}$; however, interannual variability in the observed hypoxic extent is large, for example, due to variations in freshwater discharge and nutrient load (drought versus flood years) and atmospheric weather patterns (passage of tropical storms that lead to enhanced vertical mixing and ventilation of bottom waters) (see http://www.gulfhypoxia.net).

[3] The major driver leading to the formation of hypoxia on the shelf is decay of nutrient-stimulated phytoplankton growth fueled by excessive nutrient inputs from the Mississippi/Atchafalaya River System. The Mississippi River is one of the world's largest rivers, draining about $41 \%$ of the contiguous U.S. including tile-drained cornfields in the Midwest. The latter contribute significant amounts of fertilizer-derived nitrogen to the river runoff [Goolsby et al., 2000; David et al., 2010]. Nitrate load, which made up 61\% of the total nitrogen load from 1980 to 1996 , has tripled when compared to that in the 1970s [Goolsby et al., 2000].

[4] Concerns about increasing nutrient loads prompted the formation of the Mississippi River/Gulf of Mexico Watershed Nutrient Task Force in 1996, an alliance of multiple state and federal agencies and tribal organizations. In its 2008 Action Plan, the Task Force articulated as one of three 
major goals a reduction of the hypoxic zone area to 5,000 $\mathrm{km}^{2}$ or less by 2015 through voluntary actions [Hypoxia Task Force, 2008] - a goal that is unlikely to be met. As illustrated by the Task Force Action Plan, scientific understanding about the mechanisms underlying the generation and maintenance of the hypoxic zone on the TX-LA shelf is influencing decision making at various state and federal levels. Decisions should be informed by a comprehensive understanding of the processes influencing the occurrence of hypoxia to devise effective nutrient reduction strategies and to build reasonable expectations as to what effects might be expected in response to nutrient reductions.

[5] High-resolution physical-biogeochemical models are indispensable tools for building a mechanistic understanding of cause-and-effect relationships. The objectives of this study are to present such a model, evaluate its deterministic simulations of hypoxic conditions on the TX-LA shelf against observations and to assess the sensitivity of the model's simulated hypoxia to choices that have to be made during model development. We systematically explore the effects of three choices, all of which could potentially affect hypoxia simulations, namely, the vertical resolution, the realism in horizontal boundary conditions, and the treatment of oxygen consumption at the sediment-water interface. We use an ecosystem model that has been shown to realistically reproduce many observed features of nutrient and plankton dynamics on the TX-LA shelf [Fennel et al., 2011] and that has been used successfully before to study the dynamics of another dissolved gas, inorganic carbon, on the northeastern North American shelf [Fennel and Wilkin, 2009; Previdi et al., 2009; Fennel, 2010]. In a recent study by Laurent et al. [2012], the model was extended to include phosphate as additional nutrient; however, the experiments discussed here all use the nitrogen-based model without phosphate. Here the model was extended to explicitly describe the dynamics of dissolved oxygen including air-sea gas exchange, photosynthetic production of oxygen, oxygen consumption in the water column due to respiration and nitrification, and sediment oxygen consumption. Different treatments of the latter are explored.

[6] The manuscript is organized as follows: in section 2, we first describe the physical model including the different configurations for horizontal boundary conditions (climatological observations versus output from operational models), then the biological model component and parameterizations of oxygen sources and sinks. In section 3, we discuss model results focusing initially on the areal extent of hypoxic conditions and its sensitivity to the choice of sediment oxygen consumption (SOC) parameterization and horizontal boundary treatment (section 3.1), then we discuss the vertical structure of hypoxic conditions (section 3.2), the role of vertical stratification (section 3.3), and finally assess whether hypoxic conditions are simulated in the right locations (section 3.4). Our main conclusions (section 4) are that hypoxia simulations on the TX-LA shelf are very sensitive to the treatment of SOC (a direct result of the fact that hypoxia is limited to a relatively thin layer above the bottom), that the strength of vertical stratification is an important predictor of hypoxia and that modification of physical horizontal boundary conditions can lead to dramatic differences in hypoxia simulations because vertical stratification strength can be affected by such a change.

\section{Model description}

\subsection{Physical model}

[7] We used several configurations of the Regional Ocean Modeling System (ROMS, http://myroms.org, [Haidvogel et al., 2008]) for the Mississippi/Atchafalaya outflow region. These configurations differ in terms of vertical resolution (20 or 30 vertical layers) and in the treatment of horizontal boundary conditions (climatological or more realistic conditions from operational Gulf of Mexico models), but all use the same horizontal grid (Figure 1). The models' terrain-following vertical layers are stretched to result in increased resolution near the surface and bottom. The horizontal resolution is highest near the Mississippi Delta with up to $1 \mathrm{~km}$ and lowest in the southwestern corner with $\sim 20 \mathrm{~km}$. The model uses a fourth-order horizontal advection scheme for tracers, a third-order upwind advection scheme for momentum, and the turbulence closure scheme for vertical mixing by Mellor and Yamada [1982]. The simulation period is from 1 January 2004 to 31 December 2007.

[8] In simulations with climatological boundary treatment (henceforth referred to simply as climatological simulations), radiation conditions [Flather, 1976] are imposed for the three-dimensional velocities with no mean barotropic flow. Temperature and salinity at the boundary are relaxed to a horizontally uniform monthly climatology with a timescale of 10 days for outgoing and 1 day for incoming

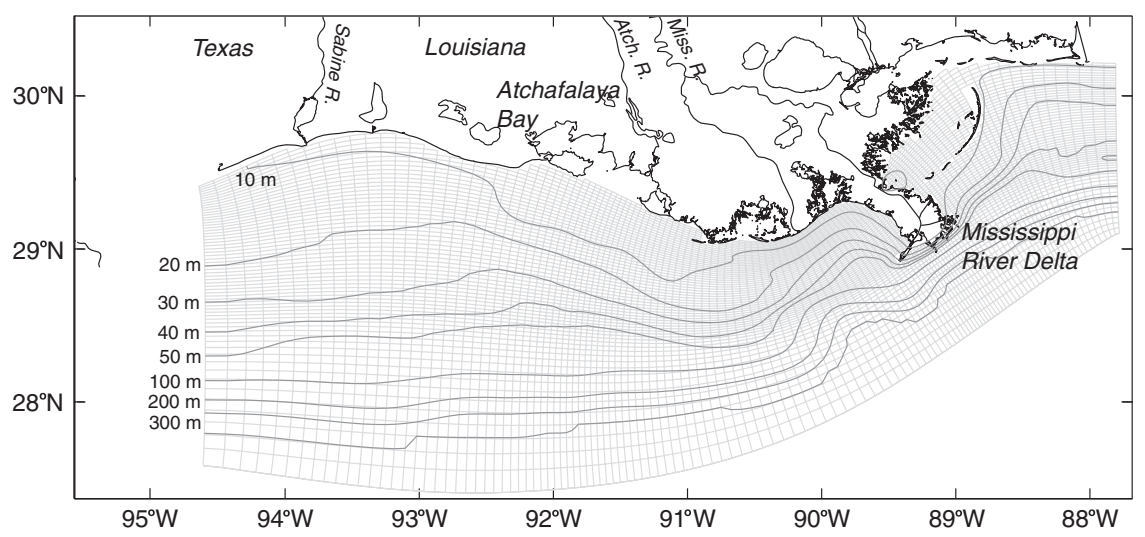

Figure 1. Model domain, grid (light gray lines) and selected isobaths (dark gray lines). 
information. All climatological simulations were initialized with an average profile of temperature and salinity (based on historical hydrographic data and assumed to be horizontally uniform) and spun up for at least 1 year. This configuration was used previously in the studies by Hetland and DiMarco [2008, 2012] and Fennel et al. [2011].

[9] In the configurations with more realistic boundary treatment, initial and daily boundary conditions were taken from two Gulf of Mexico operational models, which are subsequently referred to as parent models. A nudging region with a width of 6 grid cells was implemented along the three open boundaries in which model temperature, salinity, and baroclinic velocities are relaxed toward those of the parent models. The nudging time scale was 8 hours at the boundaries decaying to 0 inside the nudging layer. At the boundaries, radiation conditions are used for tracers and baroclinic velocities, and sea surface height and barotropic currents from the parent models are imposed.

[10] The two parent models are 1) the Gulf of Mexico operational hybrid coordinate ocean model (HYCOM) and 2) the Intra Americas Sea Nowcast Forecast System (IASNFS). HYCOM (http://www.hycom.org) [Wallcraft et al., 2009] has a horizontal resolution of $\sim 4 \mathrm{~km}$ and 20 vertical layers and assimilates observations from several sources including satellite altimetry, satellite and in situ temperatures, and vertical temperature and salinity profiles from XBTs and ARGO buoys. The IASNFS model [Ko et al., 2008] has a horizontal resolution of $\sim 6 \mathrm{~km}, 41$ vertical levels and assimilates similar observations as HYCOM. More details on the off-line nesting procedure and the parent models can be found in the study by Marta-Almeida et al. (Evaluation of model nesting performance on the Texas-Louisina continental shelf, submitted to Journal of Geophysical Research, 2013).

[11] The models are forced with 3-hourly winds from the NCEP North American Regional Reanalysis (NARR) and climatological surface heat and freshwater fluxes from the study by da Silva et al. [1994a, 1994b]. Freshwater inputs from the Mississippi and Atchafalaya Rivers use daily measurements of transport by the U.S. Army Corps of Engineers at Tabert Landing and Simmesport, respectively.

[12] The climatological model realistically captures the two distinct modes of circulation over the TX-LA shelf, namely, mean offshore flow during upwelling favorable winds in summer and mean westward (downcoast) flow during downwelling favorable winds for the rest of the year [Hetland and DiMarco, 2008]. Model skill in simulating observed salinity distributions was quantified for the climatological and nested configurations in the study by Hetland and DiMarco [2012] and Marta-Almeida et al. (submitted manuscript, 2013). respectively.

\subsection{Biological model}

[13] The biological component of our model uses the nitrogen cycle model described in the study by Fennel et al. [2006] but was extended by including dissolved oxygen as a state variable and a parameterization of the air-sea flux of oxygen as described below. The nitrogen cycle model is a relatively simple representation that includes two species of dissolved inorganic nitrogen (nitrate, NO3, and ammonium, NH4), one functional phytoplankton group, Phy, chlorophyll as a separate state variable, $C h l$, to allow for photoacclimation, one functional zooplankton group, Zoo, and two pools of detritus representing large, fast-sinking particles, LDet, and suspended, small particles, SDet.

[14] The main processes described in the model are 1) temperature, light- and nutrient-dependent phytoplankton growth with ammonium inhibition of nitrate uptake, 2) zooplankton grazing represented by a Holling-type III parameterization, 3) aggregation of phytoplankton and small detritus to fast sinking large detritus, 4) photoacclimation (i.e., a variable ratio between phytoplankton and chlorophyll), 5) linear rates of phytoplankton mortality, zooplankton basal metabolism, and detritus remineralization, 6) a second order zooplankton mortality, 7) light-dependent nitrification (i.e., oxidation of ammonium to nitrate), and 8) vertical sinking of phytoplankton and detritus. The model is shown schematically in Figure 2. For further details on model justification, equations and parameters we refer the reader to Fennel et al. [2006, 2008].

[15] Here we only report the new model equation describing the biochemical dynamics of oxygen, $O x$, as follows:

$$
\begin{aligned}
\frac{\partial O x}{\partial t} & =\mu_{\max } f(I)\left(L_{N O 3} R_{02: N O 3}+L_{N H 4} R_{O 2: N H 4}\right) P h y \\
& -2 \hat{n} N H 4 \\
& -R_{O 2: N H 4}\left(l Z o o+\hat{r}_{S D} S D e t+\hat{r}_{L D} L D e t\right)
\end{aligned}
$$

where $\mu_{\max }$ is the maximum growth rate of phytoplankton, $f(I)$ is a nondimensional light-limitation term, $L_{N O 3}$ and $L_{N H 4}$ correspond to nutrient-limitation due to nitrate and ammonium, respectively, $R_{O 2: N O 3}=138 / 16 \mathrm{~mol} \mathrm{O}_{2} / \mathrm{mol} \mathrm{NO}_{3}$ and $R_{O 2: N H 4}=106 / 16 \mathrm{~mol} \mathrm{O}_{2} / \mathrm{mol} \mathrm{NH}_{4}$ are stoichiometric ratios corresponding to the oxygen produced per mol of nitrate and ammonium assimilated during photosynthetic production of organic matter, $\hat{n}$ is the nitrification flux, $l$ is the zooplankton excretion rate, and $\hat{r}_{S D}$ and $\hat{r}_{L D}$ are the remineralization rates of small and large detritus, respectively. The first term on the right-hand side of equation (1) corresponds to the production of oxygen during photosynthesis. While phytoplankton growth is limited by the total available dissolved inorganic nitrogen (i.e., the sum of nitrate and ammonium), the corresponding oxygen gain differs depending on which nitrogen species supports photosynthesis, hence, the distinction between $L_{N O 3}$ and $L_{N H 4}$ in the first right-hand side term of equation (1). The second term represents the

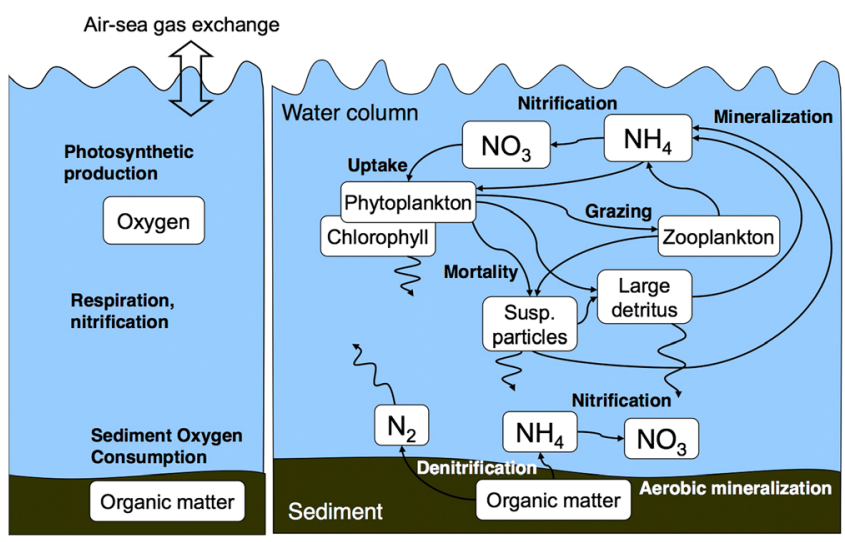

Figure 2. Schematic of the biological model. 
consumption of oxygen during oxidation of ammonium to nitrate $\left(2 \mathrm{~mol}\right.$ of $\mathrm{O}_{2}$ are consumed per mol of ammonium oxidized), and the last term corresponds to oxygen sinks due to respiration by zooplankton and heterotrophic bacteria that degrade detritus. The hats in equation (1) mark terms that have been modified compared to Fennel et al. [2006] to account for low oxygen concentrations. Specifically,

$$
\hat{r}=r \cdot \max \left[\left(\frac{O x-O x_{t h}}{k_{o x+O x-O x_{t h}}}\right), 0\right],
$$

where $k_{o x}=3 \mathrm{mmol} \mathrm{O}_{2} \mathrm{~m}^{-3}$ is an oxygen half-saturation concentration and $O x_{t h}=6 \mathrm{mmol} \mathrm{O}_{2} \mathrm{~m}^{-3}$ an oxygen threshold below which no aerobic respiration or nitrification occurs. The same formulation is used for remineralization of large and small detritus and for nitrification.

[16] In addition to the biochemical sources and sinks of oxygen, there is gas exchange across the air-sea interface, which directly affects the oxygen concentration in the top layer of the model and is parameterized as

$$
F=\frac{v k_{O 2}}{\Delta \mathrm{z}}\left(O x_{s a t}-O x\right)
$$

where $F$ (in units of $\mathrm{mmol} \mathrm{O}_{2} \mathrm{~m}^{-3}$ ) is the flux of oxygen into the top layer, $v k_{O 2}$ is the gas exchange coefficient for oxygen, $\Delta z$ is the thickness of the respective grid box, and $O x_{\text {sat }}$ is the saturation concentration of oxygen. The gas exchange coefficient is parameterized following Wanninkhof [1992] as

$$
v k_{O 2}=0.31 u_{10}^{2} \sqrt{\frac{660}{S c_{O x}}} .
$$

[17] Here $u_{10}$ is the wind speed $10 \mathrm{~m}$ above the sea surface, and $S c_{O x}$ is the Schmidt number, which we calculate as in the study by Wanninkhof [1992]. Ox $x_{\text {sat }}$ is based on the study by Garcia and Gordon [1992].

[18] In combination with the freshwater discharge described in section 2.1, the model receives inorganic and organic nutrients, specifically nitrate, ammonium, and particulate nitrogen which are based on monthly nutrient flux estimates from the U.S. Geological Survey [Aulenbach et al., 2007]. Particulate organic nitrogen fluxes are determined as the difference between total Kjeldahl nitrogen and ammonium.

[19] Three different parameterizations of sediment oxygen consumption (SOC) have been implemented and are compared in this study:

A. The option for "instantaneous remineralization" (referred to as IR) relates the flux of organic matter into the sediment to a corresponding efflux of ammonium. In IR, all organic matter that reaches the sediment is instantaneously remineralized accounting for the loss of fixed nitrogen due to denitrification. Key assumptions underlying this parameterization are that denitrification and SOC are linearly related according to the relationship presented by Seitzinger and Giblin [1996], that oxygen is consumed in the sediments only by nitrification and aerobic remineralization, and that all organic matter reaching the sediments is remineralized immediately (bottom water concentrations are updated accordingly in the same time step). The detailed derivation is given in the study by Fennel et al. [2006]. Here the parameterization was extended to include the corresponding oxygen sink. Because this parameterization accounts for denitrification (i.e., the production of biologically unavailable $\mathrm{N}_{2}$ ), it represents a sink of bioavailable nitrogen in the system. An important limitation of this parameterization is that it neglects temporal delays in SOC which occur in nature and would result in smaller SOC at the height of blooms and larger SOC after bloom events in late summer and fall and further downstream from nutrient sources.

B. We also implemented the SOC option of Hetland and DiMarco [2008] (henceforth referred to as H\&D), which was parameterized based on sediment flux observations by Rowe et al. [2002]. H\&D parameterizes oxygen uptake by the sediments dependent on bottom water oxygen concentration and temperature as

$$
\begin{aligned}
F_{S O C}^{H \& D}(T, O x)= & 6\left[\operatorname{mmol} O_{2} m^{-2} d^{-1}\right] 2^{T / 10^{\circ} \mathrm{C}} \\
& \left(1-\exp \left(-\frac{O x}{30\left[\mathrm{mmol} O_{2} m^{-3}\right]}\right)\right) .
\end{aligned}
$$

SOC is assumed to increase linearly with increasing bottom water oxygen for concentrations below $\sim 50 \mathrm{mmol}$ $\mathrm{O}_{2} \mathrm{~m}^{-3}$ and to saturate above $\sim 100 \mathrm{mmol} \mathrm{O}_{2} \mathrm{~m}^{-3}$. Temperature dependence follows the Q10-rule with SOC doubling for each temperature increase of $10^{\circ} \mathrm{C}$. Here the parameterization was extended to include a flux of ammonium into the bottom water that is proportional to the SOC flux:

$$
F_{N H 4}=-r_{N H 4: S O C} F_{S O C}
$$

with $r_{N H 4: S O C}=0.036 \mathrm{~mol} \mathrm{NH}_{4}$ per mol O${ }_{2}$. The derivation of $r_{N H 4: S O C}=$ is given in Appendix 5. With this parameterization, organic matter essentially leaves the system when sinking out of the water column, but a fraction of the nitrogen that sank out is returned to the water column as ammonium (at the rate dictated by the parameterization). This approach is more realistic than the IR parameterization in the sense that it predicts larger sediment oxygen consumption when water temperatures are highest and microbial decomposition of sedimentary organic matter is accelerated (i.e., in summer). IR predicts the highest rate of oxygen consumption when the organic sinking flux is largest (i.e., in spring). However, an important limitation of the H\&D parameterization is that it does not account for any direct effect of changes in nutrient load on SOC, essentially disconnecting the two. The same limitation applies to the next parameterization.

C. The third SOC option is based on the linear relationship between SOC and bottom water oxygen suggested by Murrell and Lehrter [2011] (henceforth referred to as M\&L) and is based on their sediment flux 
measurements. The $\mathrm{M} \& \mathrm{~L}$ relationship was modified slightly here by forcing the linear fit to be zero for zero bottom water oxygen and by including temperature dependence following the Q10-rule resulting in the following:

$$
F_{O 2}^{M \& L}(T, O x)=0.0235[m] 2^{T / 10^{\circ} \mathrm{C}} O x\left[\operatorname{mmol} O_{2} m^{-3}\right] .
$$

[20] The SOC flux observations from Murrell and Lehrter [2011] are smaller than those observed by Rowe et al. [2002], leading to generally smaller SOC fluxes with the M\&L option compared to H\&D (Figure 3). Ammonium fluxes are determined according to equation (6) as for H\&D.

[21] The three SOC parameterizations result in an oxygen drawdown in the bottom-most grid cells (simulating the effect of oxygen diffusing into the sediments) and are separate from and in addition to oxygen drawdown in the water that results from remineralization of detritus, nitrification, etc.

[22] The biological variables $\mathrm{NH}_{4}, \mathrm{Phy}, \mathrm{Chl}$, Zoo, Sdet, and LDet were initialized with small constant values, while $N O 3$ and $O x$ were initialized with horizontally homogenous mean winter profiles based on available in situ data. All biological simulations were spun up for 1 year. At the open boundaries $N O 3$ and $O x$ were prescribed using the NODC

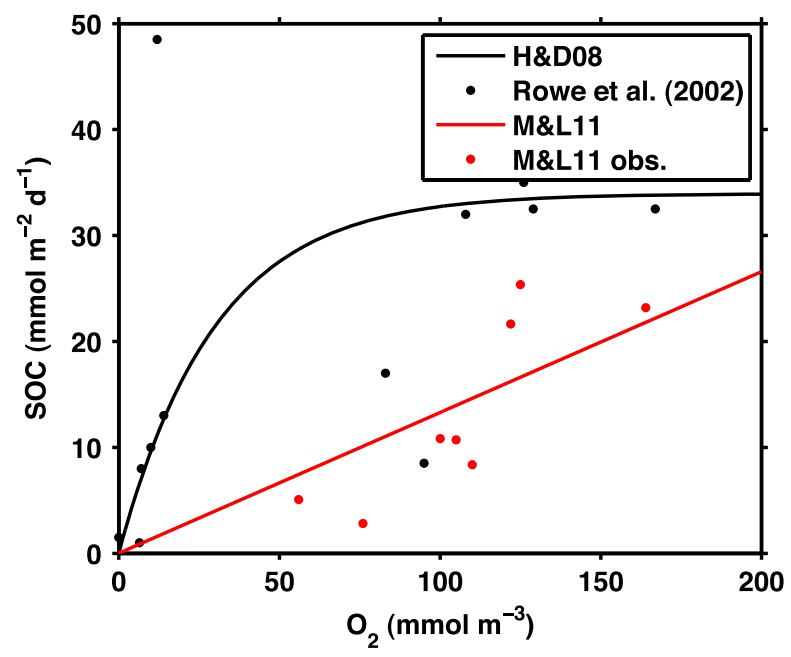

Figure 3. Parameterizations of sediment oxygen consumption (SOC) of Hetland and DiMarco [2008] (black line) and Murrell and Lehrter [2011] (red line) at $25^{\circ} \mathrm{C}$ and observations of Rowe et al. [2002] (black dots) and Murrell and Lehrter [2011] (red dots).
World Ocean Atlas. All other biological state variables at the boundary were set to small positive values.

[23] We present results from 4 years of simulation from 1 January 2004 to 31 December 2007. An overview of all the simulations discussed here is given in Table 1.

\section{Results and discussion}

\subsection{Spatial extent of simulated hypoxic conditions}

[24] The spatial extent of hypoxic conditions has been used historically as an important metric for the TX-LA shelf, for example, in monitoring interannual variability of hypoxia [Rabalais et al., 2002], as dependent variable in statistical hypoxia models [Greene et al., 2009; Forrest et al., 2011; Feng et al., 2012] and as target for nutrient reduction strategies put forth by the Hypoxia Task Force [2008]. Simulated hypoxic areal extent (temporal means and ranges) for the end of July (coincident with the hypoxia monitoring cruises of Rabalais et al. [2002]) are given in Table 2, and time series from selected simulations are shown in comparison to the observed spatial extent in Figures 4 and 5 and Figure S1 in the Online Supplement.

[25] Of the three simulations with different treatments of sediment oxygen consumption (SOC) but the same climatological boundary conditions and 20 vertical layers, simulation B20clim (with H\&D SOC parameterization) simulates the observed hypoxic extent best and agrees with the observed extent in all 4 years (Figure 4). Simulation A20clim (with IR) simulates hypoxic extent equally well in 2004 but underestimates the observed extent in the other 3 years. Almost no hypoxic conditions are produced in simulation C20clim (with M\&L SOC parameterization).

[26] No systematic differences in simulated hypoxic extent result from changes in vertical resolution (i.e., an increase in vertical resolution from 20 to 30 layers) in the climatological runs. This is illustrated for two different SOC parameterizations (IR and H\&D) in Figure S1 (see Online Supplement).

[27] Changes in the boundary conditions, however, lead to one systematic difference, namely, a doubling in hypoxic extent for simulation B30IAS (with IASNFS boundary conditions; Figure 5). The hypoxic extent simulated in $\mathrm{B} 30 \mathrm{HYC}$ (with HYCOM boundaries) is very similar to that in the climatological simulation B30clim.

[28] It should be noted that uncertainties in model parameters, initial and boundary conditions and forcing (which can only be known approximately) can lead to amplified uncertainties in hypoxia simulations (Mattern, P., et al., Uncertainty in hypoxia predictions for the TX-LA shelf, submitted to Journal of Geophysical Research, 2013) (see Figure S2 for an example of uncertainty in hypoxic extent

Table 1. Overview of Model Simulations

\begin{tabular}{|c|c|c|c|}
\hline Run & SOC Treatment & Vertical Resolution & Horizontal Boundary Treatment \\
\hline A20clim & instantaneous remineralization & 20 layers & climatological \\
\hline B20clim & H\&D SOC parameterization & 20 layers & climatological \\
\hline C20clim & M\&L SOC parameterization & 20 layers & climatological \\
\hline A30clim & instantaneous remineralization & 30 layers & climatological \\
\hline B30clim & H\&D SOC parameterization & 30 layers & climatological \\
\hline A30HYC & instantaneous remineralization & 30 layers & HYCOM \\
\hline B30HYC & H\&D SOC parameterization & 30 layers & HYCOM \\
\hline A30IAS & instantaneous remineralization & 30 layers & IASNFS \\
\hline B30IAS & H\&D SOC parameterization & 30 layers & IASNFS \\
\hline
\end{tabular}


FENNEL ET AL.: SENSITIVITY OF HYPOXIA PREDICTIONS

Table 2. Observed and Simulated Hypoxic Area at the End of July (in $\left.10^{3} \mathrm{~km}^{2}\right)^{\mathrm{a}}$

\begin{tabular}{|c|c|c|c|c|c|c|c|c|c|c|c|c|}
\hline & & 2004 & & & 2005 & & & 2006 & & & 2007 & \\
\hline \multirow[t]{2}{*}{ Observed } & \multicolumn{3}{|c|}{11.0} & \multicolumn{3}{|c|}{10.1} & \multicolumn{3}{|c|}{9.4} & \multicolumn{3}{|c|}{15.3} \\
\hline & Min & Mean & Max & Min & Mean & $\operatorname{Max}$ & Min & Mean & Max & Min & Mean & $\operatorname{Max}$ \\
\hline A20clim & 10.5 & 12.9 & 14.3 & 1.6 & 2.8 & 3.9 & 1.9 & 3.3 & 5.9 & 5.7 & 7.0 & 9.3 \\
\hline B20clim & 10.8 & 18.2 & 24.6 & 2.4 & 5.6 & 11.8 & 4.3 & 8.0 & 14.3 & 7.8 & 11.3 & 17.7 \\
\hline C20clim & 0.4 & 1.5 & 2.8 & 0.1 & 0.2 & 0.4 & 0.0 & 0.2 & 0.5 & 0.2 & 0.6 & 1.2 \\
\hline A30clim & 13.0 & 15.2 & 16.3 & 2.2 & 3.4 & 5.0 & 1.3 & 2.6 & 4.8 & 4.0 & 5.0 & 7.4 \\
\hline B30clim & 10.8 & 20.1 & 27.5 & 2.7 & 7.3 & 14.7 & 5.0 & 8.6 & 14.4 & 7.7 & 10.7 & 16.8 \\
\hline A30HYC & 2.9 & 6.3 & 9.7 & 0.1 & 0.6 & 1.1 & 0.4 & 1.3 & 2.6 & 1.6 & 2.2 & 3.3 \\
\hline B30HYC & 14.4 & 21.3 & 24.7 & 3.9 & 8.0 & 13.5 & 11.2 & 15.8 & 21.5 & 11.3 & 14.7 & 18.6 \\
\hline A30IAS & 6.0 & 11.0 & 15.2 & 0.6 & 1.6 & 3.1 & 0.5 & 1.9 & 3.8 & 2.4 & 3.5 & 5.1 \\
\hline B30IAS & 29.5 & 37.3 & 40.3 & 15.9 & 23.0 & 33.1 & 26.6 & 32.9 & 41.0 & 25.7 & 30.7 & 35.7 \\
\hline
\end{tabular}

a Minimum, mean, and maximum extent of hypoxic area during the July monitoring cruises are reported for the simulations. The area was estimated by linearly interpolating the observed oxygen concentrations onto the model grid with the help of Matlab's grid data function and then calculating the area with oxygen concentrations below the hypoxic threshold.

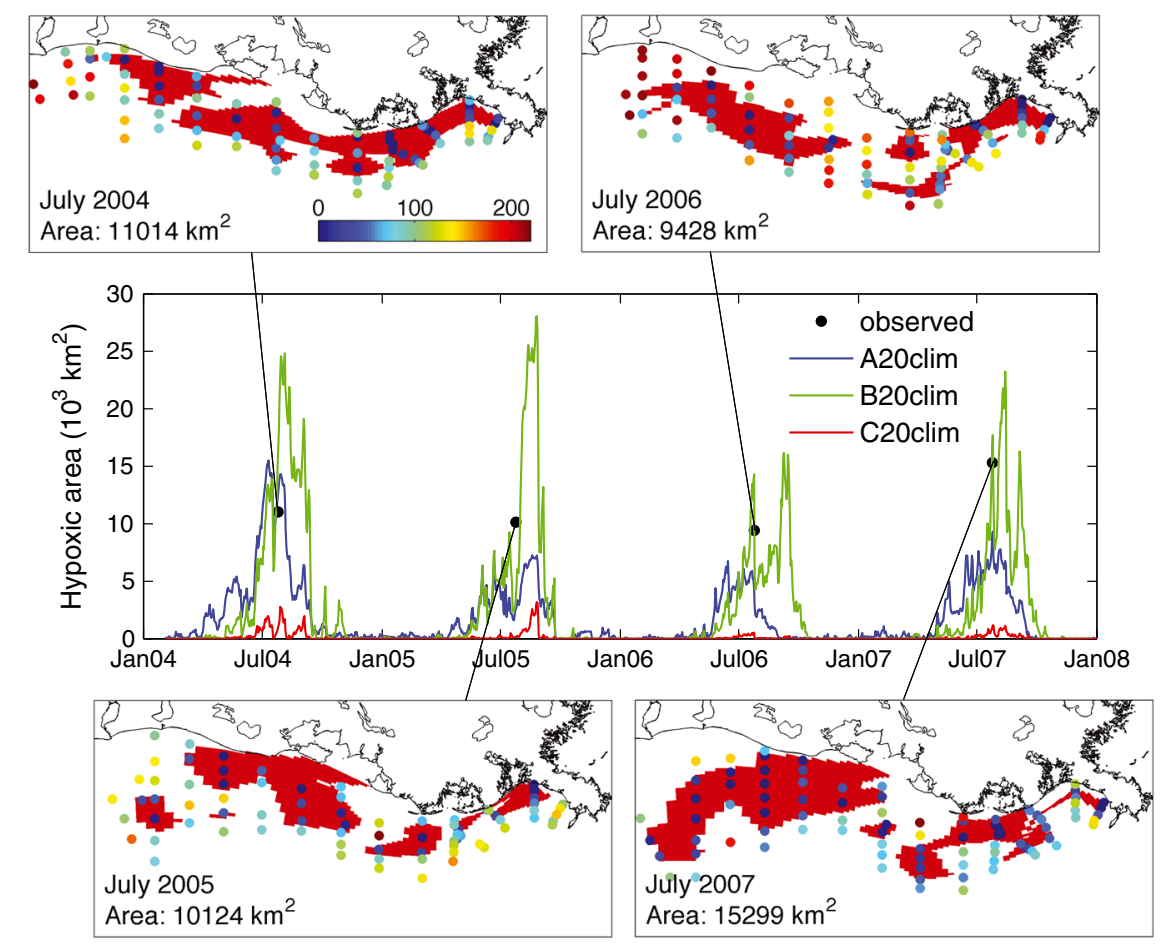

Figure 4. (Middle panel) Time series of simulated hypoxic extent for the three different treatments of sediment oxygen consumption: A20clim (blue line), B20clim (green line), and C20clim (red line) and observed extent in late July (black dots). See Table 1 for acronyms. Also shown are the observed bottom oxygen concentrations (colored dots) and the inferred hypoxic area (red area) for the years 2004 (top left), 2005 (bottom left), 2006 (top right), and 2007 (bottom right). The observed bottom oxygen concentrations (colored dots) are in units of $\mathrm{mmol} \mathrm{O}_{2} \mathrm{~m}^{-3}$ and correspond to the colour scale shown in the top left panel.

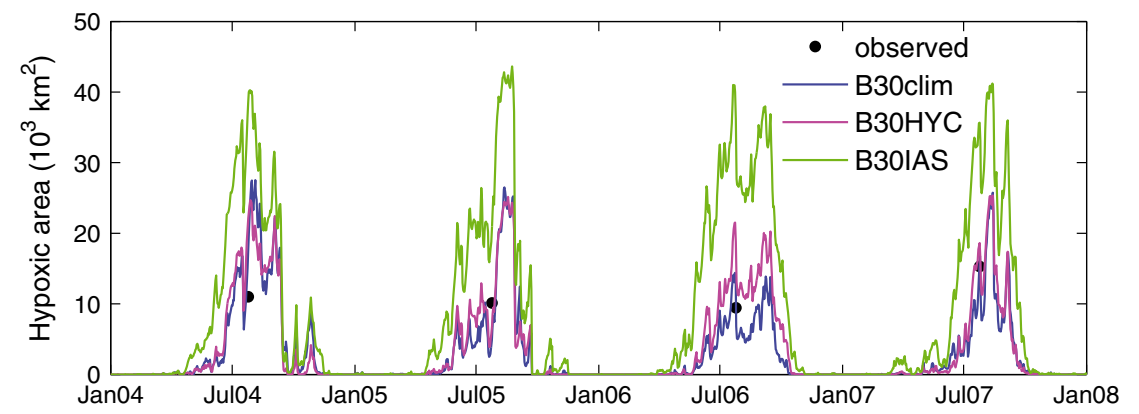

Figure 5. Time series of simulated hypoxic extent with the H\&D SOC parameterization for the three different boundary treatments: B30clim (blue line), B30HYC (magenta line), and B30IAS (green line) and observed extent in late July (black dots). 
resulting from an assumed 20\% error in freshwater discharge). Of course, the estimate of the observed hypoxic extent, although represented without error bars, is based on necessarily incomplete station observations and contains errors as well (we estimated the hypoxic extent here by linearly interpolating the observed bottom oxygen concentrations onto the model grid with Matlab's grid data function, then summing the area of all grid cells that are hypoxic according to the interpolated observations), for example, the 2005 extrapolation on the inner shelf side of the hypoxic area at the mouth of Atchafalaya Bay may be an overestimate. Another important limitation of using the spatial extent of hypoxia as metric for comparisons between model and observations is that a model may well simulate the right hypoxic extent but in the wrong location, hence for the wrong reasons.

[29] Also obvious in Figure 4 is that large temporal changes in simulated hypoxic extent can occur over short time scales (a few days) and that there are systematic differences in simulated hypoxic extent between the different formulations on longer (monthly) time scales. Evaluation of these features would require highly resolved time series measurements to address variability on short time scales as well as more than one shelf-wide cruise per year to address the monthly evolution of spatial hypoxic extent.

[30] The results discussed so far raise three questions which will be considered next:

[31] 1. Why are simulated hypoxia so sensitive to the treatment of sediment oxygen consumption?

[32] 2. Why is hypoxic extent roughly doubled when the IASFNS boundary conditions are used?

[33] 3. Are hypoxic conditions simulated in the right locations?

\subsection{Importance of sediment oxygen consumption for the generation of hypoxic conditions}

[34] On the TX-LA shelf hypoxic conditions are often restricted to below a secondary pycnocline well below the main pycnocline, an observation that was first made by Wiseman et al. [1997]. Our model simulations show the same behavior. For example, the median thickness of the hypoxic layer in simulation B20clim is $2.6 \mathrm{~m}$ (Figure 6), while the median thickness of the layer below the main pycnocline is much larger with $8.4 \mathrm{~m}$ during hypoxic events. We defined the main pycnocline as the depth where density first exceeds the density at the surface plus $0.1 \sigma_{t}$-units and only included days and horizontal grid cells where hypoxic conditions occurred. The median thickness of the hypoxic layer differs between simulations (Table 3) but is typically less than half of the median thickness of the layer below the main pycnocline. We defined the bottom boundary layer as the layer in which density does not exceed the density at the bottom plus $0.5 \sigma_{t}$-units. In B20clim, this bottom boundary layer has a median thickness of $2.7 \mathrm{~m}$ during hypoxic events (Figure 6) and coincides with the hypoxic layer. The hypoxic layer and bottom boundary concur remarkably well in all simulations (Table 3).

[35] The fact that hypoxic conditions are typically restricted to within 2-3 m above the sediment suggests that SOC is an important contributing factor to hypoxic bottom waters. Kemp et al. [1992] suggested, based on a compilation of measured water column and sediment respiration
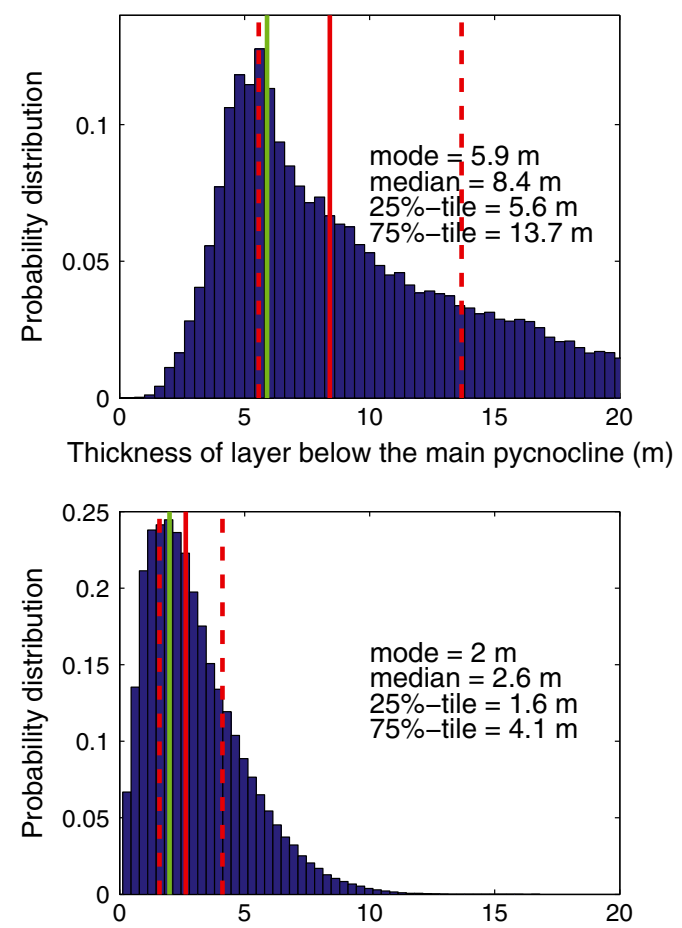

Thickness of hypoxic layer above bottom (m)

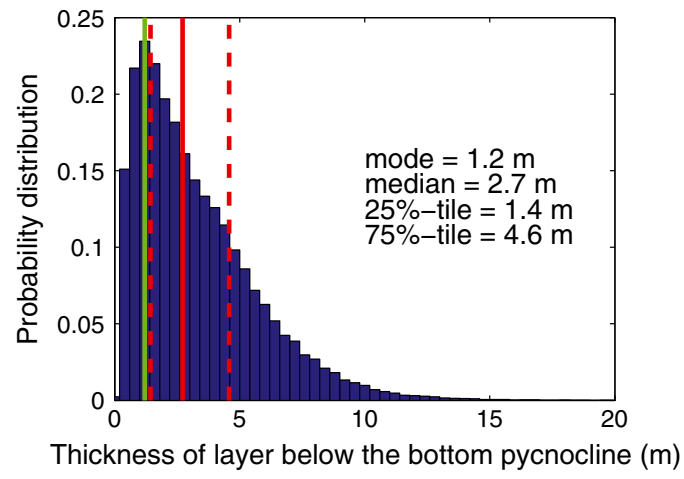

Figure 6. Probability distributions of simulated thicknesses of layer below the main pycnocline (top), layer below the oxycline of $63 \mathrm{mmol} \mathrm{O}_{2} \mathrm{~m}^{-3}$ (middle), and bottom pycnocline (bottom) for simulation B20clim. Includes days and horizontal grid cells where hypoxic conditions occurred. Main pycnocline depth was defined as depth at which density first exceeds that at the surface plus $0.1 \sigma_{t}$-units. Bottom pycnocline was defined as height from bottom at which density first exceeds that at the bottom plus $0.5 \sigma_{t}$-units. Mode and median are shown by solid green and red lines, respectively, and 25 th and 75 th percentiles are shown by dashed red lines.

rates from a number of coastal environments, that the importance of sediment respiration is inversely related to water depth. Water column respiration refers here to the consumption of oxygen due to microbial respiration measured in a sample of water, while SOC or sediment respiration refers to the consumption of oxygen by processes in the sediment, i.e., the flux of oxygen into the sediments. Kemp et al. [1992] derived an empirical relationship for the SOC fraction of total respiration. Based on this relationship, they predicted that water column oxygen sinks should exceed those 


\section{FENNEL ET AL.: SENSITIVITY OF HYPOXIA PREDICTIONS}

Table 3. Median (Med.), Mode (Mod.), 25th Percentile (25-pct), and 75th Percentile (75-pct) of Simulated Thickness of the Layer Below the Main Pycnocline, Thickness of the Hypoxic Layer, and Thickness of the Bottom Boundary Layer ${ }^{\mathrm{a}}$

\begin{tabular}{|c|c|c|c|c|c|c|c|c|c|c|c|c|}
\hline \multicolumn{5}{|c|}{ Thickness of Main Pycnocline } & \multicolumn{4}{|c|}{ Thickness of Hypoxic Layer } & \multicolumn{4}{|c|}{ Thickness of Bottom Layer } \\
\hline & 25-pct & med. & mod. & 75-pct & 25-pct & med. & mod. & 75-pct & 25-pct & med. & mod. & 75-pct \\
\hline A20clim & 5.1 & 7.5 & 5.9 & 14.0 & 1.8 & 3.0 & 2.0 & 4.8 & 1.2 & 2.1 & 1.0 & 4.6 \\
\hline B20clim & 5.6 & 8.4 & 5.9 & 13.7 & 1.6 & 2.6 & 2.0 & 4.1 & 1.4 & 2.7 & 1.2 & 4.6 \\
\hline C20clim & 4.9 & 5.8 & 5.9 & 7.1 & 0.7 & 1.2 & 0.8 & 1.8 & 0.7 & 1.1 & 0.8 & 1.6 \\
\hline A30clim & 4.0 & 6.6 & 3.8 & 12.5 & 1.8 & 3.4 & 0.9 & 6.0 & 1.0 & 1.9 & 0.9 & 4.6 \\
\hline B30clim & 4.8 & 8.0 & 3.8 & 13.6 & 1.8 & 3.2 & 1.9 & 5.1 & 1.4 & 2.8 & 1.0 & 5.2 \\
\hline A30HYC & 3.6 & 5.0 & 3.8 & 7.1 & 1.1 & 1.9 & 1.0 & 3.2 & 0.8 & 1.3 & 0.7 & 2.2 \\
\hline B30HYC & 5.3 & 8.3 & 6.0 & 14.9 & 2.2 & 3.9 & 2.4 & 5.8 & 1.6 & 3.1 & 0.9 & 5.4 \\
\hline A30IAS & 3.9 & 5.6 & 3.9 & 8.9 & 1.2 & 2.2 & 1.2 & 3.5 & 0.9 & 1.6 & 0.9 & 2.8 \\
\hline B30IAS & 6.5 & 11.9 & 6.1 & 19.2 & 2.8 & 4.3 & 3.5 & 6.3 & 2.2 & 4.0 & 2.3 & 6.4 \\
\hline
\end{tabular}

${ }^{\mathrm{a}}$ The upper limit of the latter is defined as the depth where density equals the density at the bottom plus $0.5 \boldsymbol{\sigma}_{t}$ units. All numbers are in units of m. The calculations only include days and horizontal grid cells where hypoxia was encountered. Histograms of the underlying distributions are shown for B20clim in Figure 6.

of the sediment for systems deeper than $5 \mathrm{~m}$. By relating their observed water column respiration rate in the layer below the main pycnocline to sediment oxygen consumption, Murrell and Lehrter [2011] suggested that sediments on the TX-LA shelf account for $22 \%$ of total oxygen consumption-an estimate that is consistent with the empirical relationship of Kemp et al. [1992]. We would argue that the thickness of the bottom boundary layer (i.e., the layer that actually turns hypoxic) should be applied instead of the thickness of the layer below the main pycnocline, a point that has already been made by Hetland and DiMarco [2008]. When applying the water column respiration rates of Murrell and Lehrter [2011] to a $2 \mathrm{~m}$ thick layer of water above the bottom, the SOC fraction of total respiration rises to $46 \%$. When applying the water respiration rates of Murrell and Lehrter, [2011] and the sediment respiration rates of Rowe et al. [2002], the SOC fraction rises to $60 \%$. Both of these estimates are also consistent with the empirical relationship of Kemp et al. [1992].

[36] It should be noted that a main pycnocline is a prerequisite for the existence of a secondary pycnocline as discussed by Hetland and DiMarco [2008] Overall stratification of the water column thus continues to be a useful index for hypoxia and will be discussed next.

\subsection{Importance of Stratification for the Generation of Hypoxic Conditions}

[37] Vertical stratification of the water column is generally thought to be a prerequisite for the occurrence of hypoxia in coastal systems as stratification is a barrier to vertical oxygen supply from the surface. We analyzed the correlation between bottom water oxygen concentrations and stratification in our simulations. As a measure of stratification, we calculated the potential energy anomaly $\left(\phi ; \mathrm{J} \mathrm{m}^{-3}\right)$ defined by Simpson [1981] as

$$
\phi=\frac{1}{h} \int_{-h}^{0}(\rho-\bar{\rho}) g z d z \quad \text { with } \quad \bar{\rho}=\frac{1}{h} \int_{-h}^{0} \rho d z,
$$

where $\mathrm{h}$ is the depth of the water column, $\rho$ is density, $\mathrm{g}$ is the gravitational acceleration, and $\mathrm{z}$ is the vertical coordinate. The value of $\phi$ is equivalent to the amount of work required per unit volume to vertically homogenize the water column through mixing [Simpson, 1981]. $\phi$ has been widely used as a measure for stratification strength (see the study by Burchard and Hofmeister [2008] and references therein).

[38] Time series of stratification index $\phi$ and bottom oxygen concentration are shown in Figure 7 for a representative station on the shelf for each of the four simulated years of B20clim. As expected, $\phi$ and bottom oxygen are anticorrelated, meaning that stronger stratification corresponds to lower bottom oxygen. The correlations are strong with absolute values of $r$ larger than 0.70 in all years except for 2006 when absolute correlation is 0.45 . Absolute correlation coefficients are even higher for May to August, i.e., the period

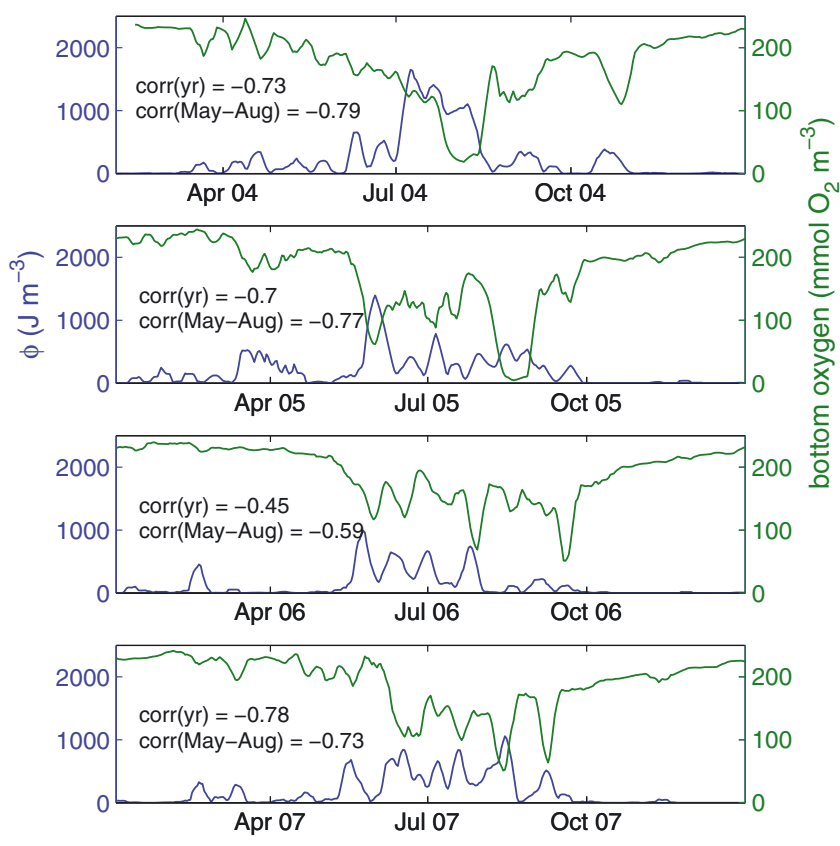

Figure 7. Simulated time series of potential energy anomaly ( $\phi$; blue line) and bottom oxygen concentration (green line) for a representative station on the TX-LA shelf (station is indicated by a magenta dot in Figure 7) for the years 2004-2007 for simulation B20clim. Time series was lowpass filtered with a filter window of 1 week to remove time scales shorter than 1 week. The correlation coefficient between both variables over the whole year and for the months May to August is given as well. 


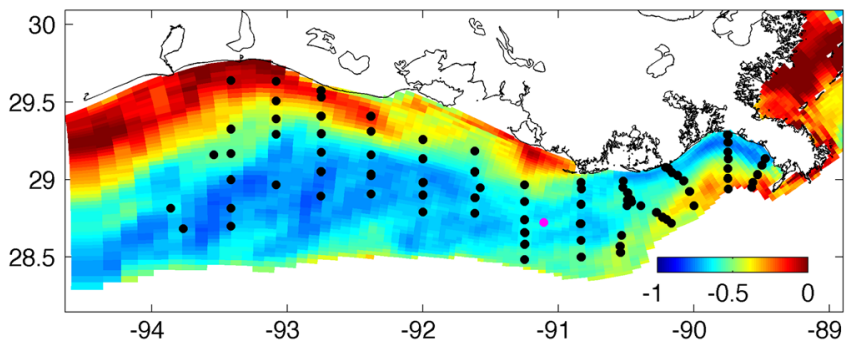

Figure 8. Spatial distribution of temporal correlations between stratification index $\phi$ and bottom oxygen concentration over the whole simulation period for B20clim. Also shown are stations (black dots) that had hypoxic bottom waters during at least one of the July monitoring cruises between 2004 and 2007. The magenta dot indicates the site for which time series are shown in Figure 6.

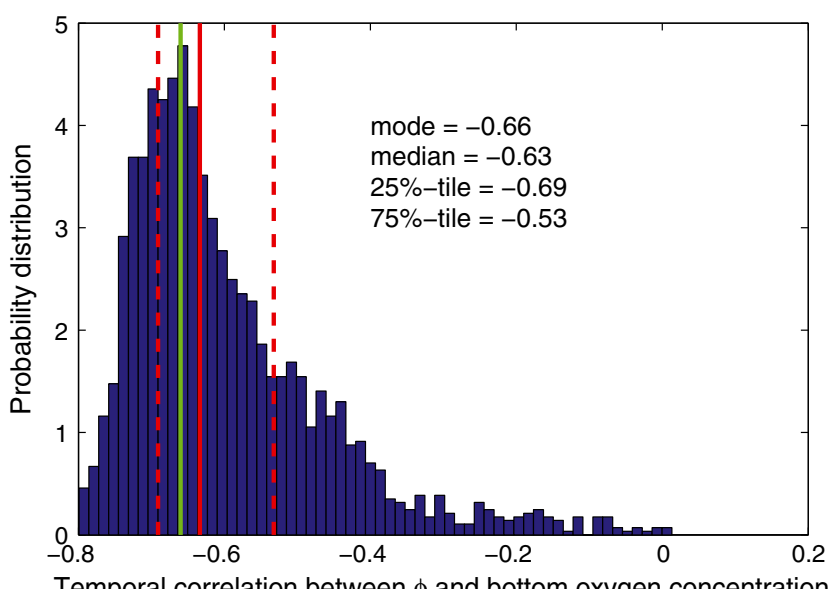

Figure 9. Probability distribution of simulated temporal correlation coefficients between $\phi$ and bottom oxygen for B20clim. Mode and median are indicated by green and red lines, 25th and 75th percentiles by dashed red lines.

Table 4. Median, Mode, 25th Percentile (25-pct), and 75th Percentile (75-pct) of Temporal Correlation Between Stratification Index $\phi$ and Bottom Oxygen Concentration in Percent ${ }^{\mathrm{a}}$

\begin{tabular}{lcccc}
\hline & \multicolumn{4}{c}{ Temporal Correlation } \\
\hline & $25-$ pct & Median & Mode & 75 -pct \\
A20clim & -71 & -65 & -63 & -61 \\
B20clim & -69 & -63 & -66 & -53 \\
C20clim & -68 & -62 & -62 & -51 \\
A30clim & -73 & -66 & -69 & -59 \\
B30clim & -71 & -66 & -70 & -58 \\
A30HYC & -75 & -70 & -73 & -61 \\
B30HYC & -73 & -67 & -72 & -55 \\
A30IAS & -74 & -70 & -74 & -62 \\
B30IAS & -76 & -70 & -76 & -58 \\
\hline
\end{tabular}

${ }^{\mathrm{a}}$ Histogram of the underlying distribution is shown for B20clim in Figure 9.

during which hypoxia forms, except for 2007 where the absolute value of the annual correlation coefficient is 0.78 while the May to August value is 0.73 . This strong correlation between stratification index and bottom oxygen concentration is not an anomaly as can be seen in the map
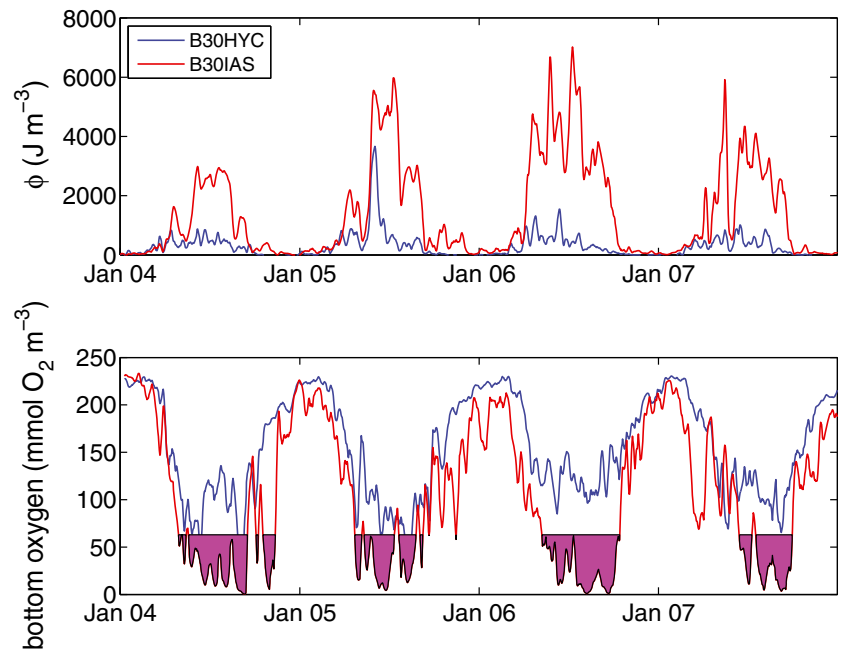

Figure 10. Time series of stratification index (top panel) and bottom oxygen concentration (bottom panel) at a shelf station close to the western boundary of the model domain for simulations B30HYC (blue lines) and B30IAS (red lines). Oxygen concentrations below the hypoxic threshold of $63 \mathrm{mmol} \mathrm{O}_{2} \mathrm{~m}^{-3}$ are highlighted in magenta.

in Figure 8 and the histogram in Figure 9. The map in Figure 8 illustrates that the two variables are strongly correlated over most of the shelf except for the shallow nearshore area west of Atchafalaya Bay. Most of the monitoring stations that were found to be hypoxic at least once between 2004 and 2007 (shown as black dots in Figure 8) have absolute correlation coefficients of 0.50 and higher. Absolute values of mode and median of the correlation coefficients are 0.60 and 0.63 , respectively (Figure 9). Strong correlations are found for all simulations (Table 4).

[39] The question arises whether the differences in areal extent of hypoxic conditions simulated by B30HYC and B30IAS result from differences in strength of stratification. It should be noted that the biological model configuration is identical in both simulations (i.e., the same biological initial and boundary conditions and parameterizations are used). The only difference between B30HYC and B30IAS is in their physical boundary conditions. In Figure 10, time series of $\phi$ and bottom oxygen are shown for a shelf station close to the western boundary of the domain for both simulations. The stratification index is significantly higher for B30IAS while bottom oxygen concentrations are significantly lower and at hypoxic levels for extended periods every summer. The stratification index in B30HYC is much lower, and bottom oxygen concentrations are higher, reaching hypoxic levels only occasionally.

[40] Thus, the significant difference in simulated hypoxic conditions between B30HYC and B30IAS (a doubling of hypoxic extent in the latter) must be due to differences in the physical boundary conditions with the latter model producing stronger vertical stratification because of its boundary conditions. It is noteworthy that this difference was not diagnosed in the salinity skill assessment of Marta-Almeida et al. (submitted manuscript, 2013), who compared the skill of both models in simulating observed salinity profiles and found that skill scores were practically indistinguishable. 

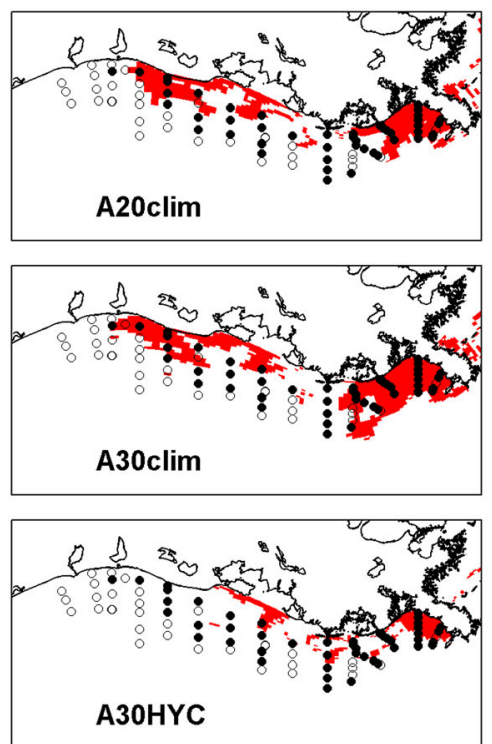
Figure 11. Simulated hypoxic area (red) and sampling
itoring cruise for late July of 2004. Filled circles indicat
sampling. The simulated area is shown for the half-way
One possible explanation is that model skill is similar for
both models east of $93^{\circ} \mathrm{W}$ where most of the observed profiles are located, while stratification (and thus simulated hypoxic conditions) differ most strongly west of $93^{\circ} \mathrm{W}$.

\subsection{Spatial Comparison of Simulated Hypoxic Conditions}

[41] The simulated hypoxic area during the hypoxia monitoring cruise in late July of 2004 and the corresponding hypoxia observations are shown in Figure 11 for all simulations. When comparing the different treatments of the sediment oxygen sink for climatological boundary conditions (top row in Figure 11), it is obvious that treatment A (IR) generates hypoxia closer to the river freshwater sources (i.e., near the Mississippi Delta and Atchafalaya Bay) while treatment $\mathrm{B}(\mathrm{H} \& \mathrm{D})$ generates hypoxic conditions also at some of the deeper shelf stations. Treatment C (M\&L) simulates almost no hypoxia.

[42] To assess the effects of the different vertical resolutions and different boundary conditions, one can compare all the A treatments and all the B treatments. In both cases, $\mathrm{A}$ and $\mathrm{B}$, the increase in vertical resolution does not lead to qualitative changes, although the shape of the hypoxic area differs slightly between simulations. Slight changes are to be expected because of the turbulent nature of the circulation on the shelf and the resulting uncertainty in distribution features for small perturbations to the model (Mattern, P., et al., submitted manuscript, 2013).

[43] In the A treatment switching from climatological to more realistic physical boundary conditions (i.e., HYCOM or IASNFS) decreases the simulated hypoxic area, while in the B treatment hypoxic area increases for the more realistic boundary conditions. The decrease in treatment $\mathrm{A}$ is a direct consequence of the fact that more organic matter is transported off the shelf in the simulations with realistic horizontal boundary conditions and a more dynamic circulation (see Figures S3 and S4 in Online Supplement). In simulation
A30clim, more organic matter is remineralized on the shelf leading to more oxygen consumption and thus a larger hypoxic region. Hypoxia simulations with the B treatment are more sensitive to stratification on the shelf and the increase in hypoxic area for the more realistic boundary conditions is due to an increase in stratification over the outer shelf. The most pronounced difference, however, is the increase in hypoxic area in the B treatment when switching from climatological or HYCOM boundaries to IASNFS. In the previous section, we have shown that this increase is due to an increase in stratification west of $93^{\circ} \mathrm{W}$. This is reflected in Figure 11 by the westward expansion of the hypoxic area (shown in red) for B30IAS compared to B30HYC.

[44] The same qualitative patterns with regard to SOC treatments, vertical resolution and boundary conditions hold for the other 3 years (see Figures S5-S7 in the Online Supplement).

[45] Quantitative comparisons of simulated and observed hypoxic conditions for all 4 years and all simulations are presented in Figures 12 and 13. Figure 12 shows the fraction of the total number of sampling stations for which presence or absence of hypoxia was correctly simulated (i.e., the fraction of stations with positive-positive and negative-negative hits to total number of stations). The bars show this measure using model output for the date half-way through the approximately week-long cruise (same as in Figure 11). However, the number of hypoxic stations can change within a few days (see, e.g., Figure 4). To take this variability into account, the fraction of stations simulated correctly was also calculated using model output from the first and last day of the cruise; the range is given by the error bars in Figure 12. To help gauge the metric of "fraction of stations predicted correctly," we also show how the two extreme predictions that either "all stations are hypoxic" or "no station is hypoxic" would fare. This is meant to be analogous to comparing, for example, the simulated time series of a variable like temperature or chlorophyll concentration against a climatology of the same variable to test whether the model is able to 


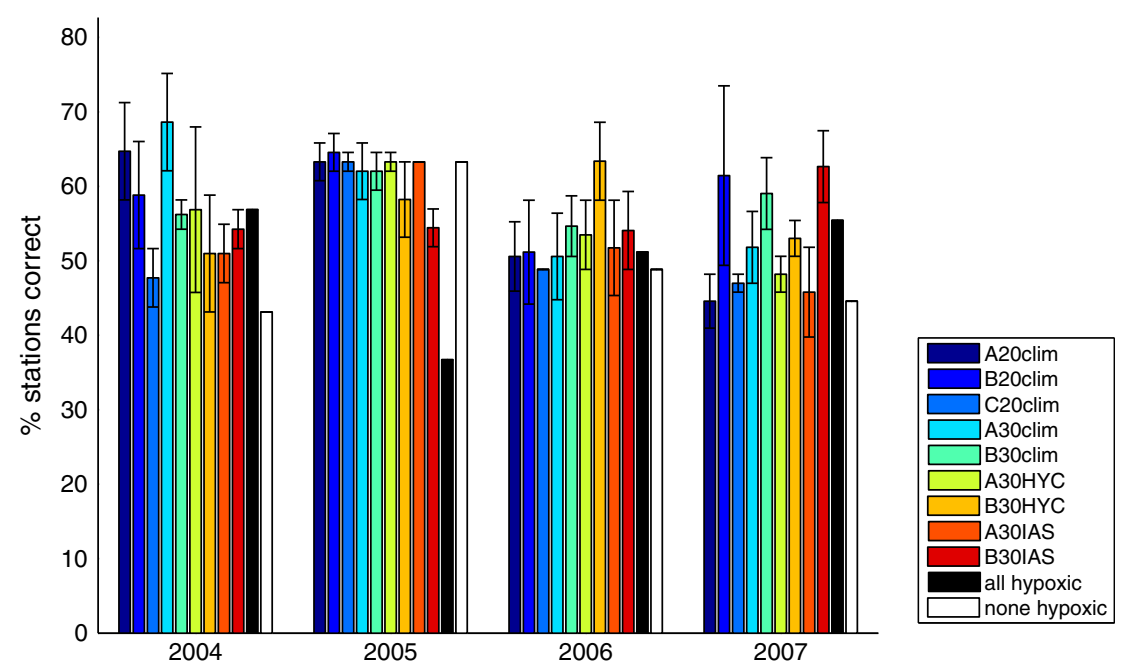

Figure 12. Percentage of sampling stations predicted correctly as hypoxic or not hypoxic during the hypoxia monitoring cruises from 2004 to 2007 . The colored bars use model output corresponding to the half-way date of the cruise. The error bars give the range when using model output for the first or last day of the cruise and can be considered as an estimate of uncertainty. Also given are the fractions of stations that are hypoxic and not hypoxic as they represent the fraction of stations that would be correctly predicted for the extreme predictions of "all stations are hypoxic" and "no station are hypoxic," respectively.

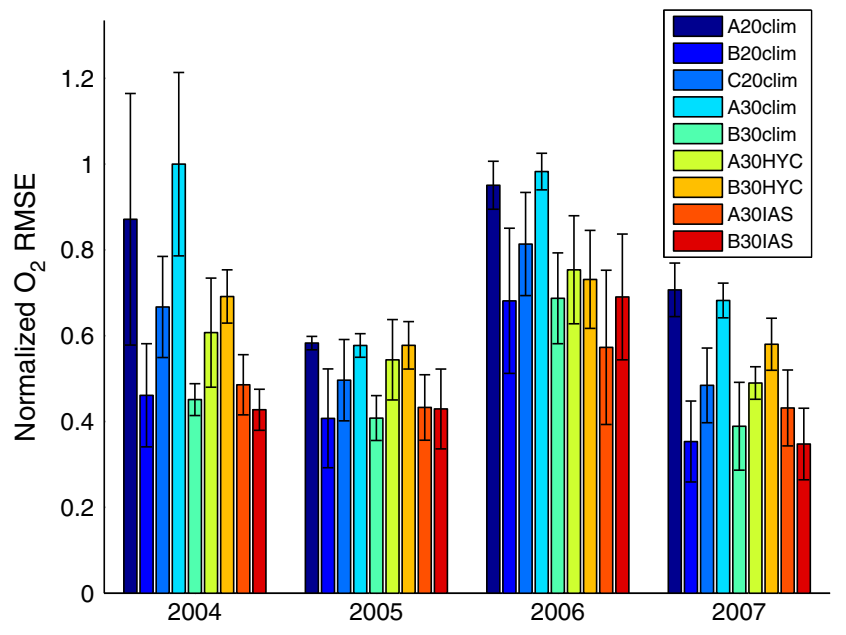

Figure 13. Root mean square error (RMSE) of dissolved oxygen between simulations and measurements from hypoxia monitoring cruises from 2004 to 2007. The colored bars use model output corresponding to the half-way date of the cruise. The error bars give the range when using model output for the first or last day of the cruise and can be considered as an estimate of uncertainty.

make better predictions than the climatology. Here we are interested whether the model is able to produce better results than would be obtained by predicting that either all stations or no station are hypoxic. For the case that "all stations are hypoxic," the metric is simply the fraction of hypoxic stations out of the total number of stations sampled. Conversely, for the case of "no station is hypoxic," it is the fraction of stations that are not hypoxic.
[46] We would like to note that not all stations are sampled each year; often cross-shelf transects are terminated when oxygenated bottom waters are encountered. The fraction of stations that are hypoxic in a given year is thus a biased measure. We would also like to point out that the fraction of stations simulated correctly by pure chance can be calculated as $p^{n} * 100 \%$ where $p$ is the probability of a station being hypoxic or not and $n$ is the number of stations. This number is very small, well below $1 \%$ for 10 stations or more, while the total number of stations during one monitoring cruise is on the order of 100 .

[47] Figure 12 shows that no model outcome is ever worse than the worst of the extreme cases "all hypoxic" and "no hypoxia." However, no model is consistently better than the better of the two extreme cases. In 2004, the climatological simulations with SOC treatment A simulate about $65 \%$ of the stations correctly, more than the better of the extreme cases "all hypoxic." In 2005, all models are on par with the better of the extreme case ("no hypoxia") at about $63 \%$ except for B30HYC and B30IAS. In 2006 simulation, $\mathrm{B} 30 \mathrm{HYC}$ is notably better than all others and the extreme cases. In 2007, only the B treatments (except B30HYC) do better than the better extreme case of "all hypoxic".

[48] Figure 13 shows the normalized RMSE of bottom water oxygen between the simulations and observations. In the climatological simulations, the error is consistently higher for the A treatment, but this difference disappears in the nested simulations where errors tend to be smaller and the A and B treatments often have similar errors. Another systematic difference is that among the nested simulations, those with HYCOM boundary conditions tend to have slightly larger errors than those with IASNFS boundaries. This is despite the fact that B30IAS simulates an unrealistically large spatial extent of hypoxia (twice the size simulated by B30HYC). 
[49] According to these metrics none of the SOC or boundary treatments consistently outperforms others. It is noteworthy that the treatment with IASNFS boundaries performs as good as or better than other models according to both metrics despite its propensity to overpredict hypoxic conditions west of $93^{\circ} \mathrm{W}$. This shows that reliance on a limited set of skill metrics can be problematic.

\section{Conclusions}

[50] Hypoxia simulations for the TX-LA shelf are very sensitive to the size of the sediment oxygen sink. Modelsimulated hypoxic extent for the three parameterizations that were tested here (instantaneous remineralization, a parameterization by Hetland and DiMarco [2008] and one by Murrell and Lehrter [2011]) varied significantly. Of these three parameterizations, the one by Hetland and DiMarco [2008] performed best in simulating the observed hypoxic extent, while instantaneous remineralization slightly underestimated the observed extent and the parameterization of Murrell and Lehrter [2011] led to almost no hypoxia. We would like to emphasize that the parameterizations of Hetland and DiMarco [2008] and of Murrell and Lehrter [2011] were used here to study model sensitivity to SOC, model resolution, and physical forcing. Neither of these parameterizations accounts for the effects of changing nutrient loads on SOC; thus, neither would be appropriate for scenario simulations with varying nutrient loads.

[51] On the TX-LA shelf, hypoxic conditions are restricted to a relatively thin layer above the sediment unlike, for example, Chesapeake Bay where hypoxic conditions occur in the bottom waters of a relatively deep channel with restricted circulation and extend tens of meters above the bottom up to the main pycnocline [Pierson et al., 2009]. In our simulations, hypoxic conditions are typically constrained to a $2-3 \mathrm{~m}$ thick bottom boundary layer which we defined operationally as the layer where density does not exceed that at the bottom by more than $0.5 \sigma_{t}$-units. A direct consequence is the sensitivity of hypoxia simulations to the rate of sediment oxygen consumption because the latter is of similar magnitude as water-column respiration when integrated over the bottom boundary layer only. It follows that an adequate resolution of near bottom stratification and sediment oxygen consumption are crucial for properly simulating hypoxia on the TX-LA shelf.

[52] On the TX-LA shelf stratification strength (expressed by the potential energy anomaly) and bottom water oxygen concentrations are highly correlated in time over most of the shelf (the exception is the shallow, near-shore area west of Atchafalaya Bay where correlation coefficients tend to be smaller than 0.50 ). Mode and median of absolute correlation coefficients are always larger than 0.60 , regardless of which sediment oxygen parameterization is used. Stratification strength is thus an important determinant of hypoxic conditions.

[53] Replacing the physical climatological boundary conditions with more realistic conditions from HYCOM and IASNFS, both data-assimilative operational forecast models for the Gulf of Mexico, resulted in large differences in simulated hypoxic extent for IASNFS boundaries but not for HYCOM. With IASNFS boundaries, the hypoxic extent roughly doubles which is due to increased stratification west of $93^{\circ} \mathrm{W}$. These differences in stratification were not picked up by the salinity skill assessment of Marta-Almeida et al. (submitted manuscript, 2013), nor were the differences in bottom oxygen concentrations picked up by our skill metrics (percent of sampling stations simulated correctly as hypoxic or not, RMSE of bottom oxygen concentration). According to the latter two skill metrics the configuration with IASNFS boundaries performs as good or sometimes better than the other configurations. It is important to recognize that conclusions about one model formulation performing better than others do depend on the metric used. Our results here show that the statistical measures RMSE and "fraction of stations predicted correctly" are not appropriate for the given model and available observation data set. Metrics like the spatial extent of hypoxic conditions are more useful. One reason for this is that differences in hypoxia simulations appear west of $93^{\circ} \mathrm{W}$ where almost no sampling occurred. Thus we would like to caution against relying on a single or a few closely related skill metrics.

\section{Appendix A: Sediment Oxygen Consumption Parameterization}

[54] Here we derive the value of $\boldsymbol{r}_{N H 4}$ : SOC which relates the SOC flux to its corresponding efflux of ammonium. We made the following assumptions:

[55] 1. Organic matter is remineralized via two pathways: aerobic oxidation and coupled nitrification-denitrification.

[56] 2. Net oxygen consumption only occurs during aerobic carbon oxidation and nitrification.

[57] 3. Denitrification and sediment oxygen consumption are linearly related according to the relationship of Seitzinger and Giblin [1996]:

$F_{D N F}\left[\mathrm{mmol} \mathrm{N} \mathrm{m} \mathrm{d}^{-1}\right]=0.105\left[\mathrm{~mol} \mathrm{~N} / \mathrm{mol} \mathrm{O}_{2}\right] \mathrm{SOC}$ $\left[\mathrm{mmol} \mathrm{O} \mathrm{m}^{-2} \mathrm{~d}^{-1}\right.$ ] (A1)(see also Fennel et al. [2009] for a larger, more recent compilation of observations validating this relationship).Let $x \in[0,1]$ be the fraction of carbon oxidation that occurs through denitrification. Then, assuming the stoichiometries as in Fennel et al. [2006], for $1 \mathrm{~mol}$ of organic carbon to be remineralized, $106(1-x)+169.6 x=$ $106+63.6 x \mathrm{~mol} \mathrm{O}_{2}$ are consumed. The value of $\mathrm{x}$ can be determined using relationship A1 as $84.8 x=0.105$ $(106+63.6)$, hence $x=0.14$. In other words, $14 \%$ of organic matter is denitrified, and $86 \%$ is oxidized aerobically. The corresponding oxygen consumption is $114.9 \mathrm{~mol} \mathrm{O}_{2}$ $(0.86 * 106 \mathrm{~mol}$ in aerobic remineralization and $0.14 * 169.6$ mol in coupled nitrification denitrification). The corresponding production of ammonium is $4.13 \mathrm{~mol} \mathrm{NH}_{4}$ $(0.86 * 16 \mathrm{~mol}$ in aerobic remineralization and $-0.14 * 84.8+0.14 * 16=-9.63 \mathrm{~mol}$ in coupled nitrification-denitrification). Hence, for $1 \mathrm{~mol} \mathrm{O}_{2}$ consumed, 4.13/ $114.9=0.036 \mathrm{~mol} \mathrm{NH}_{4}$ are produced.

[58] Acknowledgments. We would like to thank three anonymous reviewers for their constructive comments on an earlier version of this manuscript. This work was supported by NOAA CSCOR grants NA06N0S4780198 and NA09N0S4780208 and the U.S. IOOS Coastal Ocean Modeling Testbed. NOAA NGOMEX publication no. 173. K.F. was also supported by NSERC and CFI. 


\section{FENNEL ET AL.: SENSITIVITY OF HYPOXIA PREDICTIONS}

\section{References}

Aulenbach, B., H. Buxton, W. Battaglin, and R. Coupe (2007), Streamflow and Nutrient Fluxes of the Mississippi-Atchafalaya River Basin and Subbasins for the Period of Record Through 2005. Open-File Report 2007-1080, US Geological Survey, http://toxics. usgs. gov/pubs/of2007-1080/report_site_map. html

Burchard, H., and R. Hofmeister (2008), A dynamic equation for the potential energy anomaly for analysing mixing and stratification in estuaries and coastal seas, Estuarine, Coastal Shelf Sci., 77, 679-687.

da Silva, A., C. Young-Molling, and S. Levitus (1994a), Atlas of Surface Marine Data 1994, Vol. 3, Anomalies of Fluxes of Heat and Momentum. NOAA Atlas NESDIS 8.

da Silva, A., C. Young-Molling, and S. Levitus (1994b), Atlas of Surface Marine Data 1994, vol. 4, Anomalies of Fresh Water Fluxes, NOAA Atlas NESDIS 9.

David, M., L. Drinkwater, and G. McIsaac (2010), Sources of nitrate yields in the Mississippi River Basin, J. Environ. Qual., 39, 1657-1667.

Feng, Y., S. F. DiMarco, and G. A. Jackson (2012), Relative role of wind forcing and riverine nutrient input on the extent of hypoxia in the Northern Gulf of Mexico, Geophys. Res. Lett., 39, L09601.

Fennel, K., J. Wilkin, J. Levin, J. Moisan, J. O'Reilly, and D. Haidvogel (2006), Nitrogen cycling in the Middle Atlantic Bight: Results from a threedimensional model and implications for the North Atlantic nitrogen budget, Global Biogeochem. Cycles, 20, GB3007, doi:10.1029/2005GB002456.

Fennel, K., J. Wilkin, M. Previdi, and R. Najjar (2008), Denitrification effects on air-sea $\mathrm{CO}_{2}$ flux in the coastal ocean: Simulations for the northwest North Atlantic, Geophys. Res. Lett., 35, L24608, doi:10.1029/ 2008GL036147.

Fennel, K., et al. (2009), Modeling denitrification in aquatic sediments, Biogeochemistry, 93, 159-178.

Fennel, K., and J. Wilkin (2009), Quantifying biological carbon export for the northwest North Atlantic continental shelves, Geophys. Res. Lett. 36, L18605 doi:10.1029/2009GL039818

Fennel, K. (2010), The role of continental shelves in nitrogen and carbon cycling: Northwestern North Atlantic case study, Ocean Sci., 6, 539-548.

Fennel, K., R. Hetland, Y. Feng, and S. DiMarco (2011), A coupled physical-biological model of the Northern Gulf of Mexico shelf: Model description, validation and analysis of phytoplankton variability, Biogeosci., 8, 1881-1899.

Flather, R. (1976), A tidal model of the northwest European continental shelf, Mem. Soc. R. Sci. Liege, 10, 141-164.

Forrest, D. R., R. D. Hetland, and S. F. DiMarco (2011), Multivariable statistical regression models of the areal extent of hypoxia over the Texas-Louisiana Shelf, Environ. Res. Lett., 6, 045002.

Garcia, H., and L. Gordon (1992), Solubility of oxygen at different temperature and salinity, Limnol. Oceanogr., 37, 1307-1312.

Goolsby, D., W. Battaglin, B. Aulenbach, and R. Hooper (2000), Nitrogen flux and sources in the Mississippi River Basin, Sci. Total Environ., 248 , $75-86$

Greene, R., J. Lehrter, and J. Hagy (2009), Multiple regression models for hindcasting and forecasting midsummer hypoxia in the Gulf of Mexico, Ecol. Appl., 19, 1161-1175.
Haidvogel, D., et al. (2008), Ocean forecasting in terrain-following coordinates: Formulation and skill assessment of the Regional Ocean Modeling System, J. Comput. Phys., 227, 3595-3624.

Hetland, R., and S. DiMarco (2008), How does the character of oxygen demand control the structure of hypoxia on the Texas-Louisiana continental shelf?, J. Mar. Syst., 70, 49-62.

Hetland, R., and S. DiMarco (2012), Skill assessment of a hydrodynamic model of the circulation over the Texas-Louisiana continental shelf, Ocean Modell., 43/44, 64-76.

Hypoxia Task Force (2008), Mississippi River/Gulf of Mexico Watershed Nutrient Task Force, Gulf Hypoxia Action Plan 2008 for Reducing, Mitigating, and Controlling Hypoxia in the Northern Gulf of Mexico and Improving, Water Quality in the Mississippi River Basin, Washington, DC.

Kemp, W. M., P. A. Sampou, J. Garber, J. Turtle, and W.R. Boynton, (1992), Seasonal depletion of oxygen from bottom waters of Chesapeake Bay: roles of benthic and planktonic respiration and physical exchange processes, Mar. Ecol. Prog. Ser., 85, 137-152.

Ko, D. S., P. J. Martin, C. D. Rowley, and R. H. Preller (2008), A realtime coastal ocean prediction experiment for MREA04, J. Mar. Syst., 69, 17-28.

Laurent, A., K. Fennel, J. Hu, and R. Hetland (2012), Simulating the effects of phosphorus limitation in the Mississippi and Atchafalaya River plumes, Biogeosci., 9, 4707-4723, doi:10.5194/bg-9-4707-2012.

Mellor, G., and T. Yamada (1982), Development of a turbulence closure model for geophysical fluid problems, Rev. Geophys., 20, 851-875.

Murrell, M.C., and Lehrter, J. (2011), Sediment and lower water column oxygen consumption in the seasonally hypoxic region of the Louisiana continental shelf, Estuaries Coasts, 34, 912-924.

Previdi, M., K. Fennel, J. Wilkin, and D. B. Haidvogel (2009), Interannual Variability in Atmospheric $\mathrm{CO}_{2}$ Uptake on the Northeast U.S. Continental Shelf, J. Geophys. Res., 114, G04003, doi:10.1029/2008JG000881.

Pierson, J. J., M. R. Roman, D. G. Kimmel, W. C. Boicourt, and X. Zhang (2009), Quantifying changes in the vertical distribution of mesozooplankton in response to hypoxic bottom waters, J. Exp. Mar. Biol. Ecol. Suppl., 381, S74-S79.

Rabalais, N., R. Turner, and W. Wiseman Jr (2002), Gulf of Mexico Hypoxia, aka "The Dead Zone", Annu. Rev. Ecol. Syst., 33, 235-263.

Rowe, G. T., M. E. C. Kaeki, J. W. Morse, G. S. Boland, and E. G. E. Briones (2002), Sediment community metabolism associated with continental shelf hypoxia, northern Gulf of Mexico, Estuaries, 25(6), 1097-1106.

Seitzinger, S., and A. Giblin (1996), Estimating denitrification in North Atlantic continental shelf sediments, Biogeochemistry, 35, 235-260.

Simpson, J. H. (1981), The shelf-sea fronts: implications of their existence and behaviour, Phil. Trans. R. Soc. Lond. A, 302, 531-546.

Wallcraft, A. J., E. J. Metzger, and S. N. Carroll (2009), Software Design Description for the HYbrid Coordinate Ocean Model (HYCOM), Version 2.2, Tech. Rep., Naval Research Laboratory, Stennis Space Center, MS

Wanninkhof, R. (1992), Relationship between wind speed and gas exchange, J. Geophys. Res., 97, 7373-7382.

Wiseman, W. N. Rabalais, R. Turner, S. Dinnel, and A. MacNaughton (1997), Seasonal and interannual variability within the Louisiana coastal current: stratification and hypoxia, J. Mar. Syst., 12, 237-248. 